\title{
Machine Replication of Human Perusing using Optical Character Recognition with Tesseract
}

\author{
D. Vimala, P. Nandhini, R. Elankavi
}

\begin{abstract}
Optical Character Recognition is the machine replication of human perusing. Electronic Conversion of examined pictures where picture can be type composed or printed content. It is executed utilizing Google's open source Optical Character Recognition programming called Tesseract. The OCR accepts picture as the information, gets content from that picture and afterward changes over it into whatever other language that the client needed. This framework can be helpful in different applications like banking, legitimate industry, explorers' different ventures, and home and office robotization. It for the most part intended for individuals who are unfit to peruse any sort of content archives and to diminish the weight of information passage occupations.[4]
\end{abstract}

Keywords: Co-channel disturbance, Inter signal interference, variety, Least mean rectangular, recursive square that is mean $S$ ample matrix inversion, steady modulus algorithm.

\section{INTRODUCTION}

Optical character affirmation is the mechanical or electronic difference in pictures of made, composed by hand or printed content into machine-encoded content. It is the least requesting system for digitizing printed and translated messages with the objective that they can be viably looked, set away more moderate partner, appeared and changed on the web, and used in various other taking care of errands, for instance, language elucidation and substance mining. This development empowers machine to see the substance normally. It takes after blend of eye and cerebrum of human body.[1,2] An eye can see the substance from the photos yet extremely the cerebrum shapes similarly as deciphers that removed substance examined by eye. Being created of robotized OCR structure, couple of issues can occur.

First: there is next to no unmistakable distinction between certain letters and digits for PCs to get it. For instance it may be troublesome for the PC to separate between digit " 0 " and letter "o". Second: It may be exceptionally hard to remove content, which is installed in dim foundation or imprinted on different words or illustrations.

In 1955, the primary business framework was introduced at the per user's overview, which utilized OCR to enter deals report into a PC and after that after OCR strategy has turned out to be useful in automating the physical office records. It is

Revised Manuscript Received on December 11, 2019

* Correspondence Author

D.Vimala, Department of CSE, Bharath Institute of Higher Education and Research, Chennai, Tamilnadu, India.Email:vimalamuthu3@gmail.com

P.Nandhini, Department of CSE, Bharath Institute of Higher Education and Research, Chennai, Tamilnadu, India. Email:pnandhinisuresh@gmail.com

R. Elankavi, Department of CSE, Bharath Institute of Higher Education and Research, Chennai, Tamilnadu, India. Email:kavirajcse@gmail.com a technique to find and perceive content put away in a picture, for example, a jpeg or a gif picture, and convert the content into a PC perceived structure, for example, ASCII or unicode. OCR changes over the pixel portrayal of a letter into its proportional character portrayal.[5,6] OCR has various advantages. Numerous organizations have an expansive accumulation of paper structures and records. Looking through these records by hand may take quite a while, and it is just normal to try to robotize this procedure. One way is check the records and store them as pictures on the PC, at that point perform optical character acknowledgment on the filtered pictures to remove the printed data into isolated content documents. Various devices for programmed content pursuit through content records as of now exist. So the principle unsolved issue is performing OCR precisely and proficiently. Indeed, even online picture seeks are exploring different avenues regarding performing OCR on pictures in their file of sites so as to deliver increasingly precise outcomes.

\section{TYPES OF OCR}

\section{A. Sorts of OCR's}

Character affirmation began as in front of timetable as 1870 when Carey made the retina scanner, which is an image transmission system using photocells. It is used as a manual for the ostensibly disabled by the Russian analyst Tyurin in 1900. In any case, the first machines appeared in the beginning of the 1960s with the headway of the modernized PCs.

It is the principal gone through OCR was recognized as a data taking care of use to the business world. The first machines are depicted by the "constrained" letter shapes which the OCRs can scrutinize. These pictures were uncommonly planned for machine examining, and they didn't look ordinary. The important advertised OCR of this age was IBM 1418, which was planned to scrutinize a one of a kind IBM printed style, 407. The affirmation system was format planning, which differentiates the character picture and a library of model pictures for each character of every text style.

OCR empowers countless applications. Amid the good 'ol days, OCR has been utilized for mail arranging, bank check perusing and mark confirmation . Furthermore, OCR can be utilized by associations for computerized structure preparing in spots where countless is accessible in printed structure. Different employments of OCR incorporate preparing service charges, identification approval, pen processing and mechanized number plate 
acknowledgment and so forth [3,4].The techniques depended on the basic examination approach. Critical endeavors for institutionalization were additionally made in this period. An American standard OCR character set: OCR-A textual style (Figure 1) was characterized, which was intended toencourage optical acknowledgment, albeit still comprehensible to people. An European textual style OCR-B (Figure 1) waslikewise planned and portrayed by the OCR of complex archives intermixing with content, designs, tables and scientific images, unconstrained transcribed characters, shading reports, low-quality uproarious records, and so on. Among the business items, postal location perusers, and perusing helps for the visually impaired are accessible in the market. These days, there is much inspiration to give mechanized record investigation frameworks. OCR adds to this advancement by giving methods to change over vast volumes of informationnaturally.

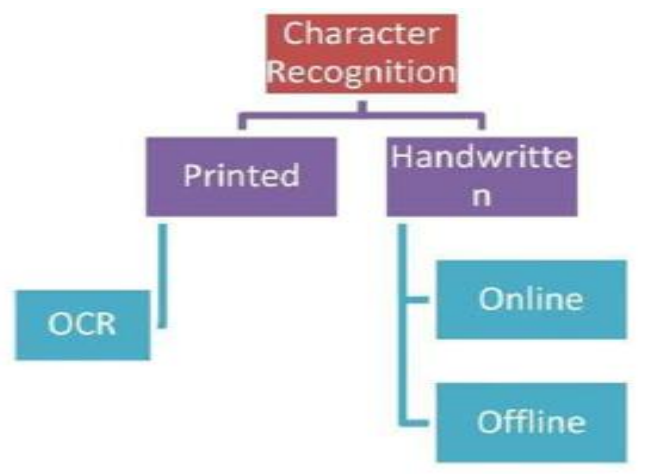

Fig .1Types of OCR

\section{B. First generation OCR systems}

Countless and licenses publicize acknowledgment rates as high as $99.99 \%$; this gives the feeling that robotization issues appear to have been understood. Disappointment of some genuine applications demonstrate that execution issues still exist on composite and corrupted reports (i.e., loud characters, tilt, blending of textual styles, and so on.) and that there is still space for advancement. Different techniques have been proposed to expand the precision of optical character recognizers. Truth be told, at different research labs, the test is to create vigorous techniques that expel however much as could be expected the typographical and commotion limitations while keeping up rates like those given by restricted text style business machines. Along these lines, current dynamic explore zones in OCR incorporate penmanship acknowledgment, and furthermore the printed typewritten adaptation of non-Roman contents (particularly those with a substantial number of characters).

\section{Qualities of proposed system}

* Detecting the character's in a picture.

* Displaing the content acquired from extraction of picture.

* Translating the acquired substance into alluring language.

\section{Utilization's of OCR}

OCR empowers countless applications. Amid the good 'ol days, OCR has been utilized for mail arranging, bank check perusing and mark confirmation . Also, OCR can be utilized by associations for computerized structure preparing in spots where countless is accessible in printed structure. Different employments of OCR incorporate preparing service charges, identification approval, pen registering and mechanized number plate acknowledgment and so forth .

\section{E. Third generation OCR systems}

Despite these broad research endeavors, the machine's capacity to dependably peruse content is still far underneath the human. Consequently, ebb and flow OCR inquire about is being done on improving precision and speed of OCR for various style archives printed/written in unconstrained conditions. There has not been accessibility of any open source or business programming accessible for complex dialects like Urdu or Sindhi and so forth.

Present day PCs can speak to more than four billion hues. To speak to each shading, PCs require thirty-two bits at that point. For shading pictures, this implies each pixel will expend something like four bytes of memory. Be that as it may, optical character acknowledgment is shading free- $\mathrm{a}$ dark letter is precisely the same as a red letter. Binarization is a technique to decrease shading pictures to two hues, high contrast. High contrast pictures just require a solitary piece for every pixel, rather than thirty-two for shading pictures.

\section{F.Characteristics of proposedsystem}

* Detecting the character's in an image.

* Displaying the text obtained from extraction of image.

* Translating the obtained content into desirable language.

\section{ARCHITECTURE OF THE OCR SYSTEM}

The Architecture contains the following 3 components. Scanner, OCR Hardware or Software, Output Interface by Fig:2.
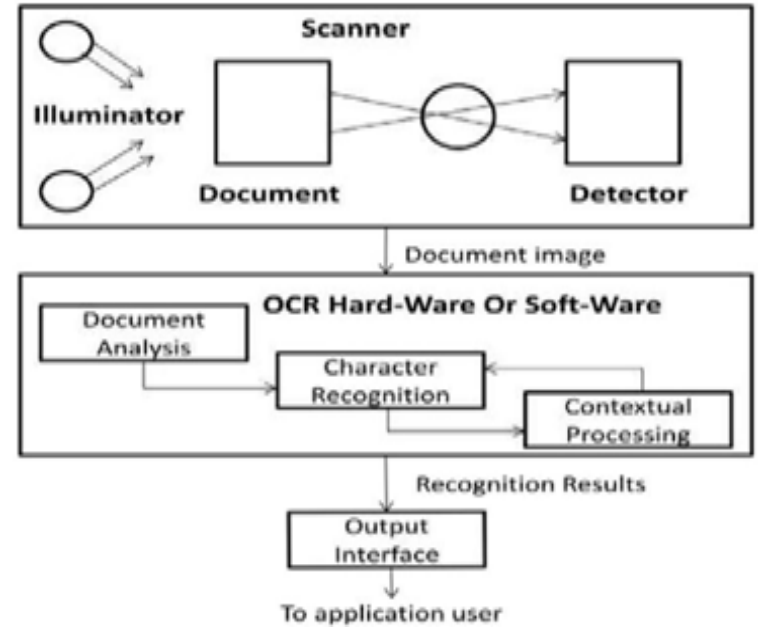

Fig 2:OCRArchitecture

\section{RESULTS AND DISCUSSION}

\section{A.Binarization}

Present day PCs can speak to more than four billion hues. To speak to each shading, PCs require thirty-two bits at that point. For shading pictures, this implies each pixel will devour no less than four bytes of memory. Nonetheless, optical character acknowledgment is shading autonomous - a dark letter is precisely the same as a red letter. 
Binarization is a strategy to decrease shading pictures to two hues, high contrast. High contrast pictures just require a solitary piece for each pixel, instead of thirty-two for shading pictures. Consistently, this incredibly lessens the unpredictability of the picture.

\section{B.Threshold Algorithm}

One calculation to perform binarization is the limit calculation. This calculation computes a subjective limit, T, which is a shading. Every pixel's shading is contrasted with the picked edge. On the off chance that the shading is over the edge, at that point the pixel is changed over to a white pixel. On the off chance that it is underneath the limit, the pixel is a dark pixel. Albeit quick and basic, this calculation has a key defect. The defect is the dependence on figuring a solitary limit for the whole picture. Frequently the edge is determined by averaging the shade of each pixel. Notwithstanding, numerous pictures may contain light or dull content which influences the limit in a negative manner. the edge delivered letters which seemed to have openings in them, since pixels that ought to have been dark, were been white. Then again, higher qualities for the limit created hazy characters. One technique to fix this blemish is called nearby binarization.[5,6]

\section{C.Local Binarization}

Instead of figuring an edge for the whole picture on the double, nearby binarization calculation dissects every pixel of the picture in a little window; as little as five by five pixels. It breaks down every pixel in respect to the pixels closest it so as to change over it into a dark or a white pixel. This adjusts for varieties in content shading, as the limit can be lower for darker content, and higher for lighter content.[7]

\section{D.Thinning}

Diminishing is a calculation to additionally decrease the measure of data in the picture to process, in this manner lessening the multifaceted nature of preparing the picture .Thinning perceives that a thick striking letter is precisely the same as a letter which is one pixel thick. More slender letters speak to a similar data all the more productively. Diminishing is a basic calculation. Also, it is quick and has no defects. Each column of pixels in the picture is checked left to right. In each line, each arrangement of associated dark pixels is supplanted by a solitary dark pixel amidst the succession. Rehashed for the whole picture, this strategy diminishes striking lines to thin, single pixel thick lines by Fig:3.

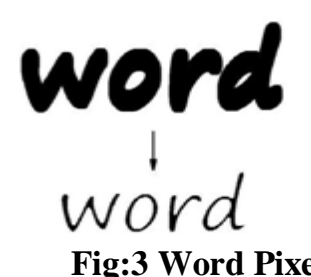

\section{E. Line finding}

The line finding computation is arranged so a skewed page can be seen without having to de-skew, along these lines saving loss of picture quality. The key bits of the method are mass isolating and line advancement. Tolerating that page Exploratory outcomes demonstrated that low estimations of

structure examination has quite recently given substance locale of a by and large uniform substance measure, an essential percentile height channel clears drop-tops and vertically reaching characters. The center height approximates the substance estimate in the zone, so it is ensured to filter through masses that are smaller than some bit of the center stature, being more then likely highlight, diacritical stamps and confusion.

The isolated masses will undoubtedly fit a model of non-covering, parallel, yet inclining lines. Masterminding and setting up the majority by $\mathrm{x}$-compose makes it possible to dole out masses to an outstanding substance line, while following the slope over the page, with remarkably reduced danger of doling out to an off kilter content line inside seeing skew. At the point when the isolated masses have been designated to lines, a least center of squares fit is used to check the baselines, and the filtered through masses are fitted by and by into the appropriate lines. The last development of the line creation process joins masses that spread by at any rate half on a dimension plane, amassing diacritical engravings with the correct base and successfully accomplice parts of some broken characters. At the point when the substance lines have been found, the baselines are fitted even more completely using a quadratic spline.

This was another first for an OCR structure, and engaged Tesseract to manage pages with twisted baselines, which are an ordinary relic in separating, and not actually at book ties. The baselines are fitted by isolating the majority into social occasions with a reasonably consistent movement for the principal straight standard. A quadratic spline is fitted to the most jam-packed portion, (thought to be the standard) by a least squares fit. The quadratic spline has the ideal position that this tally is reasonably unfaltering, anyway the hindrance that discontinuities can develop when distinctive spline partitions are required. An undeniably ordinary cubic spline may work better. All of these lines are "parallel" (the y parcel is a relentless over the entire length) and to some degree twisted. The ascender line is cyan (prints as light dim) and the dull line above it is in all actuality straight. Close examination exhibits that the cyan/diminish line is twisted regarding the straight dim line above it. [8]

While the result from a word is inadmissible, Tesseract tries by Fig:4 to improve the result by severing the mass with most exceedingly horrible assurance from the character classifier. Contender cut centers are found from depressed vertices of a polygonal conjecture of the design, and may have either another bended vertex reverse, or a line part. It may take up to 3 sets of hack centers to successfully detach joined characters from the ASCII set. A great deal of cheerful hack centers with jolts and the picked sever as a line over the chart where the ' $r$ ' contacts the ' $m$ '. Slices are executed in need demand. Any cut that fails to improve the sureness of the result is fixed, yet not completely discarded with the objective that the hack can be reauthorized later by the affiliation if fundamental.

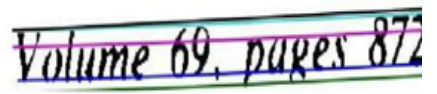

Fig:4 Tesseract Tries 


\section{Machine Replication of Human Perusing using Optical Character Recognition with Tesseract}

The Optical Character Recognition programming can be improved later on in various types of ways, for example, Training and acknowledgment paces can be expanded more prominent and more noteworthy by making it more easy to understand. Numerous applications exist where it is alluring to peruse written by hand passages. Perusing penmanship is a troublesome assignment considering the assorted varieties that exist in customary handwriting. In any case, advance is being made.An OCR isn't a nuclear procedure however includes different stages, for example, procurement, preprocessing, division, highlight extraction, grouping and post-handling. Every one of the means is talked about in detail in this paper. Utilizing a blend of these procedures, a productive OCR framework can be created as a future work. The OCR framework can likewise be utilized in various pragmatic applications, for example, number-plate acknowledgment, keen libraries and different other constant applications. In spite of the noteworthy measure of research in OCR, acknowledgment of characters for language, for example, Arabic, Sindhi Urdu still remains an open test. An outline of OCR systems for these dialects has been arranged as a future work.[9]

\section{CONCLUSION}

The Optical Character Recognition programming can be improved later on in various types of ways, for example, Training and acknowledgment velocities can be expanded more noteworthy and more prominent by making it more easy to use. Numerous applications exist where it is alluring to peruse manually written passages. Perusing penmanship is an exceptionally troublesome assignment considering the decent varieties that exist in customary handwriting. Be that as it may, advance is being made. An OCR isn't a nuclear procedure yet involves different stages, for example, obtaining, preprocessing, and division, include extraction, grouping and post-preparing. Every one of the means is talked about in detail in this paper.

\section{REFERENCES}

1. Kumaravel A., Meetei O.N.,An application of non-uniform cellular automata for efficient cryptography,2013 IEEE Conference on Information and Communication Technologies, ICT 2013,V-,I-,PP-1200-1205,Y-2013

2. Kumarave A., Rangarajan K.,Routing alogrithm over semi-regular tessellations,2013 IEEE Conference on Information and Communication Technologies, ICT 2013,V-,I-,PP-1180-1184,Y-2013

3. Dutta P., Kumaravel A.,A novel approach to trust based identification of leaders in social networks,Indian Journal of Science and Technology,V-9,I-10,PP--,Y-2016

4. Kumaravel A., Dutta P.,Application of Pca for context selection for collaborative filtering,Middle - East Journal of Scientific Research,V-20,I-1,PP-88-93,Y-2014

5. Kumaravel A., Rangarajan K.,Constructing an automaton for exploring dynamic labyrinths,2012 International Conference on Radar, Communication and Computing, ICRCC 2012,V-,I-,PP-161-165,Y-2012

6. Kumaravel A.,Comparison of two multi-classification approaches for detecting network attacks,World Applied Sciences Journal,V-27,I-11,PP-1461-1465,Y-2013

7. Tariq J., Kumaravel A.,Construction of cellular automata over hexagonal and triangular tessellations for path planning of multi-robots,2016 IEEE International Conference on Computational Intelligence and Computing Research, ICCIC 2016,V-,I-,PP--,Y-2017

8. Sudha M., Kumaravel A.,Analysis and measurement of wave guides using poisson method,Indonesian Journal of Electrical Engineering and Computer Science,V-8,I-2,PP-546-548,Y-2017

9. Ayyappan G., Nalini C., Kumaravel A., Various approaches of knowledge transfer in academic social network,International Journal of Engineering and Technology,V-,I-,PP-2791-2794,Y-2017

10. Kaliyamurthie, K.P., Sivaraman, K., Ramesh, S. Imposing patient data privacy in wireless medical sensor networks through homomorphic cryptosystems 2016, Journal of Chemical and Pharmaceutical Sciences

11. Kaliyamurthie, K.P., Balasubramanian, P.C. An approach to multi secure to historical malformed documents using integer ripple transfiguration 2016 Journal of Chemical and Pharmaceutical Sciences 9

12. A.Sangeetha,C.Nalini,"Semantic Ranking based on keywords extractions in the web", International Journal of Engineering \& Technology, 7 (2.6) (2018) 290-292

13. S.V.GayathiriDevi,C.Nalini,N.Kumar,"An efficient software verification using multi-layered software verification tool "International Journal of Engineering \& Technology, 7(2.21)2018 454-457

14. C.Nalini,ShwtambariKharabe,"A Comparative Study On Different Techniques Used For Finger - Vein Authentication", International Journal Of Pure And Applied Mathematics, Volume 116 No. 82017 , 327-333, Issn: 1314-3395

15. M.S. Vivekanandan and Dr. C. Rajabhushanam, "Enabling Privacy Protection and Content Assurance in Geo-Social Networks", International Journal of Innovative Research in Management, Engineering and Technology, Vol 3, Issue 4, pp. 49-55, April 2018.

16. Dr. C. Rajabhushanam, V. Karthik, and G. Vivek, "Elasticity in Cloud Computing", International Journal of Innovative Research in Management, Engineering and Technology, Vol 3, Issue 4, pp. 104-111, April 2018.

17. K. Rangaswamy and Dr. C. Rajabhushanamc, "CCN-Based Congestion Control Mechanism In Dynamic Networks", International Journal of Innovative Research in Management, Engineering and Technology, Vol 3, Issue 4, pp. 117-119, April 2018.

18. Kavitha, R., Nedunchelian, R., "Domain-specific Search engine optimization using healthcare ontology and a neural network backpropagation approach", 2017, Research Journal of Biotechnology, Special Issue 2:157-166

\section{AUTHORS PROFILE}

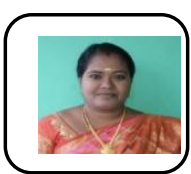

DVimala Assistant Professor, Department of Computer Science \& Engineering, Bharath Institute of Higher Education and Research, Chennai, India

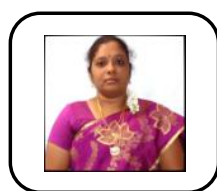

P.Nandhini Assistant Professor, Department of Computer Science \& Engineering, Bharath Institute of Higher Education and Research, Chennai, India

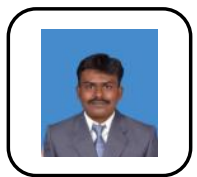

R.Elankavi Assistant Professor, Department of Computer Science \& Engineering, Bharath Institute of Higher Education and Research, Chennai, India 